\title{
The Effects of Gastric Banding in Morbid Obesity on Eating Behavior-A 3-Phase Model
}

Methods and study design: By using a survey administered to ou patients in out-patient clinics. Between the years 1998-2008 a single team of surgeons had operated on over 5000 morbid obese patients. The average age was 38 years (18-67) with average BMI of $44 \mathrm{~kg} / \mathrm{m}^{2}$ (35-65). The follow-up on these patients was made on an outpatient clinic basis, where the average time from the operation was in most of them less than 2 years.

Results: Using our results, we have formulated a model of eating habits of patients after LGB. The model included 4 different phases of eating habits, each unique in its features. This model has been validated upon more than 500 patients and has shown a significan difference between the formulated phases:

- Phase 1a-(3-6 monthspostop.) - The patientsreport an immediate sensation of fullness which enforces them to reduce the quantity and rate of the eating process.

- Phase $1 b$ - (up to 12 months post op.) - The patients are required to selection of the food types which they are able to swallow. Many of the patients report inability to swallow bread, meat and vegetables but can eat dry food such as toast or crackers.

- Phase 2- (less than 2 years post op.) - Most of the patients report inability to eat or drink in the moming and sometimes until the aftemoon.

- Phase 3 (more than 2 years post op.) - In this phase the patient's esophagus needs to be activated in order for them to eat or drink. It is achieved by a unique food or drink (hot or cold, salty or sweet etc.) which varies from one patient to the other. Once it is a chieved the patient is able to eat and drink more easily for a limited period of time.

Conclusions: Based on the results from our model, as well as ou clinical experience, we believe that one can interpret our results as those which might imply that the effect of LGB is beyond its restric tive nature, and it involves some cognitive and behavioral changes that are long lasting.

\section{Background}

Morbid Obesity is a worldwide epidemic [1,2]. The usage of diet, weight reduction medications, eating habit modifications or pharmacotherapy has been found to be inefficient, while surgical treatment is considered the only proven treatment to reduce and maintain the weight loss $[3,4]$ in short and long term, as well as

\section{Journal of Obesity and Bariatrics}

\author{
Shahar Atias ${ }^{1}$, Zvi H. Perry ${ }^{1,2 *}$, Uri Netz ${ }^{2}$, Solly \\ Mizrahi $^{1}$ and Eliezer Avinoach ${ }^{1}$
}

${ }^{1}$ Surgery ward A, Soroka University Medical Center, New York, USA ${ }^{2}$ Center for Medical Education, Ben-Gurion University of the Negev, Beer Sheva, Israel

\section{*Address for Correspondence}

Zvi Perry, MD, MA, Surgery ward A, Soroka University Medical Center, Rachel Heisler Sheinfeld, PO Box 184-H, Scarsdale, New York, USA Tel: 972-50-4893371; Fax: 972-8-6477633; E-mail: zperry@bgu.ac.i

Copyright: (c) 2015 Atias S, et al. This is an open access article distributed under the Creative Commons Attribution License, which permits unrestricted use, distribution, and reproduction in any medium, provided the original work is properly cited.

Submission: 06 April 2015

Accepted: 01 June 2015

Published: 05 June 2015

Reviewed \& Approved by: Dr. Yishai Levy, Clinical Associate Professor, Technion Faculty of Medicine, Israel

giving a valid medical monitoring over time [5,6]. Surgical weight reduction has been correlated with reduced morality over time $[5,6]$. A popular procedure to aid with this illness is Laparoscopic Gastric Banding (LGB), developed in the early 80 's of the last century by Kusmak [7]. LGB is a minimal invasive procedure, considered to be strictly a restrictive operation, and has been found to be a safe and efficient treatment for the long term morbidly obese patient. The long term natural course of patients after LGB is less understood and its implications upon the quality of life of LGB patients is ill defined.

Herein we mapped the changes in quality and life style, as well as weight reduction, in patients who underwent LGB [8]. In addition, we assessed if the effect of the banding is beyond its restrictive properties, and if these changes are due only to the restriction imposed by the band, or are there other factors involved.

\section{Patients and Methods}

Between the years 1998-2008 a single team of surgeons had operated on over 5000 morbid obese patients. The average age was 38 years (18-67) with average BMI of $44 \mathrm{~kg} / \mathrm{m}^{2}$ (35-65). The followup on these patients was made on an outpatient clinic basis, where the average BMI 5 years from the surgery was $29 \mathrm{~kg} / \mathrm{m}^{2}$ (27-34). We have used a sample of these patients, using a convenience sampling method (i.e., a non-randomized sampling). Upon this we were able to recruit more than 500 patients to be our sample. One must stress that due to our large coverage of Israel, we were able to reach most of our patients, and thus we believe that our sample is truly representative of our population.

In the clinic 250 patients are seen weekly, which can be divided to 3 major groups:

- New patients $(\sim 5 \%)$ referred for initial evaluation before determining the need of a LGB surgery.

- Patients during the first 6 months after surgery $(\sim 60 \%)$. These patients are seen monthly in the clinic for inflation of the band to an average amount of $8 \mathrm{cc}$ of normal saline.

- Patients 6 months to 10 years after surgery ( 35\%), coming 
Citation: Atias S, Perry ZH, Netz U, Mizrahi S, Avinoach E. The Effects of Gastric Banding in Morbid Obesity on Eating Behavior-A 3-Phase Model J Obes Bariatrics. 2015;2(2): 5.

to the clinic for various reasons such as eating difficulties, vomiting, desire to lose more weight, console about proper weight loss expectations and eating habits etc.

The study included the last two groups of patients which filled out a self-administered questionnaire. The questionnaire concerned personal data (age, gender, family status etc.), eating and drinking habits, quality of life aspects (ability for physical activity), daily activities (like dressing, shop for clothing), self-esteem, (satisfaction of sexual activity etc.) and finally weight and height before the surgery and in the present. We must state that all of our patients go through our clinics and this is a prime requisite to undergo LGB in our study group, due to our prior experience with non-compliant patients who suffered grave consequences like erosions and slippage due to improper handling of the Band.

\section{Procedure}

The study was evaluated and approved by the local ethics committee. Patients' demographics, surgical procedure duration and outcomes including short and long term complications were gathered through our computerized data base. Using clinic interviews patients' current status (weight, height etc.) as well as evaluation of their quality of life through our pre-formed questionnaire was evaluated.

\section{Data gathering and storage}

Data was gathered, coded and stored using SPSS software (SPSS 13.0, Chicago, IL, USA).

\section{Statistical analysis}

We analyzed the data using descriptive and analytical statistics: independent samples $t$ test, one way ANOVA and $\chi^{2}$. We also used a-parametric analysis when applicable.

Statistical significance was considered when $\mathrm{p}<0.05$.

\section{Results}

Study population included 504 patients who were visiting our out-patient clinics, of them 388 were females (77\%). Demographical and weight data are summarized in Table 1 . Their weight loss is depicted in Figure 1.

We grouped time from surgery into 5 categories - less than a year,

Table 1: Patients socio-demographics.

\begin{tabular}{|c|c|c|c|c|}
\hline \multirow[t]{2}{*}{ Demographics } & \multicolumn{2}{|c|}{ Time from surgery } & \multirow[b]{2}{*}{2 years } & \multirow[b]{2}{*}{$p$ value } \\
\hline & $<1$ year & $=1-2$ years & & \\
\hline Religion (Jew/ Muslim/Other) & $197 / 2 / 1$ & $152 / 3 / 2$ & $117 / 3 / 2$ & $0.705^{\star}$ \\
\hline Familial status (Bachelor/Married lother & $45 / 138 / 18$ & $27 / 104 / 26$ & $20 / 85 / 17$ & $0.181^{*}$ \\
\hline Weight before surgery (kg) & 122.02 & 122.4 & 122.7 & $0.957^{\star \star}$ \\
\hline Height (cm) & 166 & 164.9 & 164.6 & $0.679^{\star \star}$ \\
\hline BMI before surgery (Kg/m2) & 46.8 & 47.2 & 51.2 & 0.499 \\
\hline Age, grouped (Median) & 3 (i.e. $35-45$ ) & 3 & 3 & $0.158^{\star \star}$ \\
\hline Education level (median) & More than high school level & More than high school level & More than high school level & $0.068^{\star \star}$ \\
\hline Employment level (median) & Partial time & Partial time & Partial time & $0.186^{*}$ \\
\hline
\end{tabular}

* Chi Square test; ** Kruskal-Wallis test

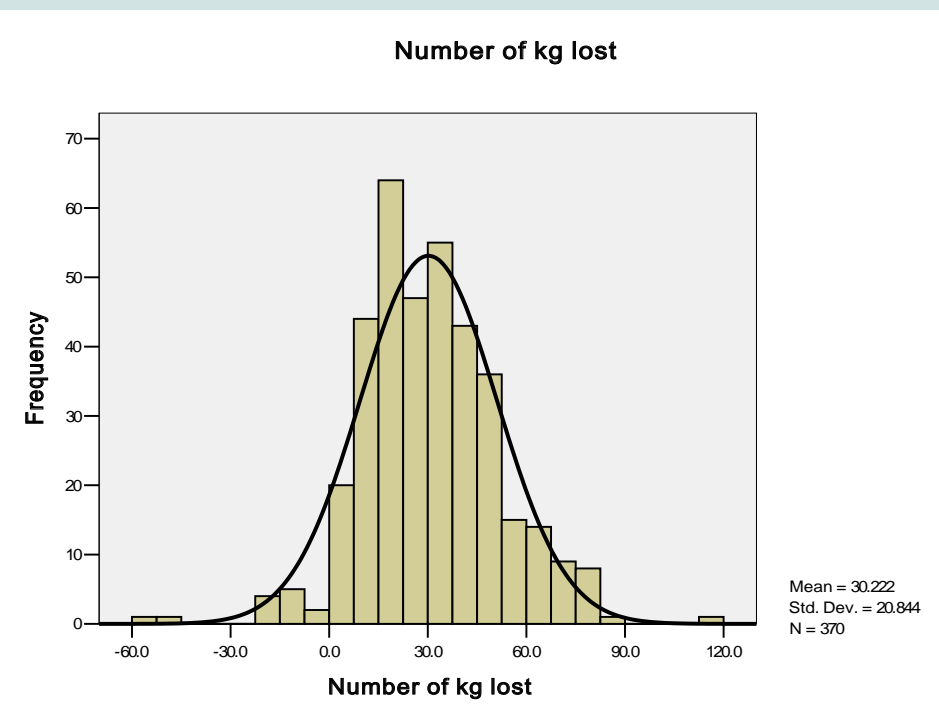

Figure 1: Weight loss after surgery. 
Citation: Atias S, Perry ZH, Netz U, Mizrahi S, Avinoach E. The Effects of Gastric Banding in Morbid Obesity on Eating Behavior-A 3-Phase Model J Obes Bariatrics. 2015;2(2): 5.

1-2 years after surgery, 2-5 years, 5-7 years and more than 7 years after surgery, 206 were less than a year after surgery (41\%), 161 (32\%) were 1-2 years after surgery, 71 (14\%) were 2-5 years after surgery, $37(7.3 \%)$ were $5-7$ years and $26(5.1 \%)$ were 7 or more years after surgery. When inquiring about their clinic visitations, we found that $98(22.7 \%)$ visited once a month, $144(33.3 \%)$ visited once every 3 months, $116(26.9 \%)$ visited every 6 months, 39 (9\%) visited once a year and $27(6.3 \%)$ less than once a year.

The average weight across all groups before and after surgery was $122 \mathrm{~kg}( \pm 20.5)$ and $91.6 \mathrm{~kg}( \pm 22)$ accordingly. The average BMI before and after surgery was $47.8 \mathrm{~kg} / \mathrm{m}^{2}( \pm 32.5)$ and $35( \pm 23.2) \mathrm{kg} /$ $\mathrm{m}^{2}$ respectively. The mean percentage of weight loss was $24 \%( \pm 16.2)$. Patients lost on average $30.4 \mathrm{~kg}$ ( \pm 21 ) after surgery (see Figure 2). When inquiring about how the patient were referred for surgery 304 patients $(60.3 \%)$ were referred or heard of the operation from a friend. 106 (21\%) were referred by a family member and 37 (7.3\%) were referred by the primary care physician. When asked about the cause for the operation, 25 (5.1\%) had the operation for Health improvement, 60 patients (12.3\%) did so to improve their quality of life and $384(78.5 \%)$ due to both of these reasons.
In 325 (64.5\%) subjects eating patterns were influenced by stress, 237 (47\%) subjects eating is influenced by illness, 121 (24\%) subjects vacation enhances their appetite, in $44(8.7 \%)$ vacation caused a diminished eating pattern and 338 (67\%) had no change in eating pattern due to vacation. Vomiting frequency after the operation - 71 patients (14.1\%) never vomited, 129 (25.6\%) vomited only rarely. On the other hand 94 patients (18.7\%) vomited more than 3 times a day.

We were able to formulate 3 distinct phases of eating habits and life style changes that are shown in Table 2. Table 1 shows basic sociodemographic variables in the 3 distinct groups.

Table 2 shows the eating habits of the different groups, along the time line.

There seems to be a specific pattern for patients in their first year after surgery, which find eating or drinking in the morning less problematic (5\% of the patients do so), whereas more experienced patients have more problems eating in the morning (23\% at $1-2$ years and as much as $30 \%$ in $2+$ years after surgery). This phenomenon was termed by our investigators "morning stiffness", as it resembles a similar phenomenon seen in rheumatoid arthritis.

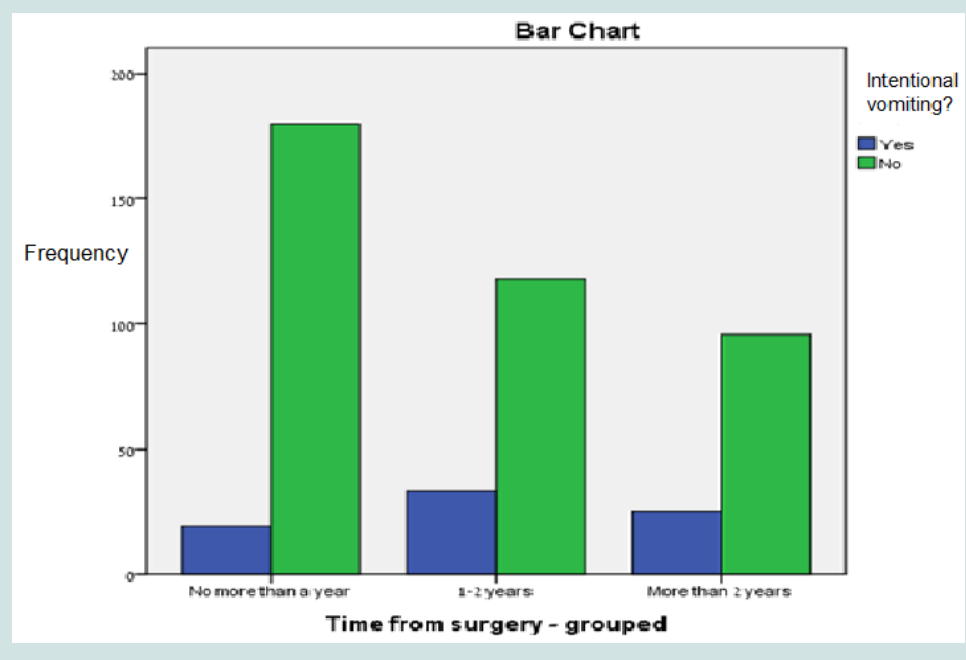

Figure 2: Intentional vomiting

Table 2: Eating habits

\begin{tabular}{|c|c|c|c|c|}
\hline & \multicolumn{2}{|l|}{ Time from surgery } & \multirow[b]{2}{*}{2 years } & \multirow[b]{2}{*}{ p value } \\
\hline & $<$ 1year & $=1-2$ years & & \\
\hline Can the patient eat at morning (Yes/No) & $190 / 10(5 \%)$ & $121 / 36(23 \%)$ & $85 / 36(29.8 \%)$ & $<0.001^{*}$ \\
\hline Food preferences (Eating and drinking/ drinking/ eating) & $95.3 \% / 2.6 \% / 2.1 \%$ & $90.1 \% / 7.8 \% / 2.1 \%$ & $87.6 \% / 9.7 \% / 2.7 \%$ & $0.102^{*}$ \\
\hline Main meal at (before noon/ afternoon /varies) & $50.3 \% / 27.3 \% / 19.7 \%$ & $32.5 \% / 43.9 \% / 23.6 \%$ & $32.2 \% / 46.3 \% / 21.5 \%$ & $<0.001^{*}$ \\
\hline Is your eating influenced by stress ( $\%$ no) & $50 \%$ & $22 \%$ & $25 \%$ & $<0.001^{*}$ \\
\hline Time from wake up till eating (morning/ noon/ afternoon) & $85 \% / 9 \% / 6 \%$ & $58 \% / 26 \% / 16 \%$ & $58 \% / 27 \% / 15 \%$ & $<0.001$ \\
\hline Number of daily meals & 2.7 & 2.3 & 2.5 & $0.024^{\star \star}$ \\
\hline Voluntary vomiting (Yes\%) & $10 \%$ & $22 \%$ & $21 \%$ & $0.003^{*}$ \\
\hline Do you suffer from vomiting (never/once daily/more than once) & $65 \% / 19 \% / 16 \%$ & $26 \% / 23 \% / 51 \%$ & $30 \% / 31 \% / 39 \%$ & $<0.001^{*}$ \\
\hline Can the patient drink at morning (Yes\%) & $5 \%$ & $23 \%$ & $30 \%$ & $<0.001^{*}$ \\
\hline Frequency of clinic visits (Mode) & Once a month & Once every 3 months & Once every 6 months & $<0.001^{*}$ \\
\hline
\end{tabular}

* Chi Square test; ** One way ANOVA 
All of the above shows that non-experienced LGB patients concentrate mainly upon external stimuli (eating due to time and not internal hunger), and it is not surprising to see that the less experienced LGB patients eating habits are much more influenced by stress (50\% in comparison to $25 \%$ in the more experienced patients). In the less experienced patients the use of voluntary vomiting is less frequent ( $10 \%$ and $20+\%$ respectively), and thus it is not surprising that they suffer less from non-intentional vomiting (19\% of the patients in the first year patients in comparison to $23 \%$ and $31 \%$ in the 1-2 years and 2+ years respectively, see Figure 2).

In accordance to our practice and the growing ability of our patients to manage their eating, the frequency of clinic visits declined from once a month in first year patients, to every 3 months in 1-2 years and to every 6 months in the $2+$ years after surgery.

\section{Discussion}

Success in maintaining weight loss after bariatric surgery requires the ability to implement long-term changes in eating habits and lifestyle. The purpose of the current study was to map food selection and eating habits during the first 3 years post-surgery. Although PubMed has more than 8000 articles upon eating habits, only 1 article was found to have a systematic review of the eating habits in LGB patients [9-12]. McGrice \& Porter believe there is a paucity of evidence-based dietary management guidelines for patients postlaparoscopic adjustable gastric banding, including no consensus recommendations for macronutrient intake [13]. Kafri et al. found similar discrepancies in the field of sleeve gastrectomy [14]. Rickers \& McSherry have found that nutritional deficiencies following bariatric surgery are very common [15]. They believe that eating habits often contribute to nutritional deficiencies, so appropriate dietary and lifestyle counseling is essential following bariatric procedures to ensure appropriate macronutrient and micronutrient status $[16,17]$. Although general guidelines exist, individual monitoring and tailoring are frequently required. This has been shown vividly in our study in which a large variance was found in many issues, but we do believe that a main theme does exist and should be implemented in guidelines that should be common knowledge to all bariatric surgeons alike. Thus, we were able to formulate a model of eating habits of LGB patients, which reflected the different stages each patient goes through after surgery. The model includes 3 different phases of eating habits, each unique in its features.

- Phase 1a (3-6 months post op.) - The patients report an immediate sensation of fullness which enforces reducing the quantity and rate of the eating process in order to prevent vomiting.

- Phase $1 b$ (up to 12 months post op.) - The patients are required to selection of the food types which they are able to swallow more easily. Many of the patients report inability to swallow bread, meat and vegetables but can eat dry food as toast or crackers.

- Phase 2 (>12 months post op.) "Morning stiffness" - Most of the patients report inability to eat or drink in the morning, noon and sometimes even later in the day. The patients usually are able to eat and drink properly in the evening and are planning their meals accordingly.
- Phase 3 (24> months post op.) "Esophageal activation" - In this phase the patient's esophagus needs to be "activated" in order for them to eat or drink. It is achieved by a unique food or drink (hot or cold, salty or sweet etc.) which varies from one patient to the other. Once it is achieved, the patient is able to eat and drink more easily for a limited period of time.

These phases vary from one patient to another and are dynamic and can overlap or appear earlier after surgery. Analyzing the data gathered from the questionnaires filled by the patients on the different periods of time after surgery, has suggested that the effect of the GB is composed of 3 different elements:

- Restrictive effect - the inflation of the band leads to decrease in the gastric inlet diameter and thus in the rate of progress of food through the band into the stomach and the total amount of food that can be consumed daily.

- Pathophysiological changes of the esophagus - during phase 1 , and with each inflation of the band, the effect on the esophagus starts immediately with the inflation but soon afterwards the esophagus adapts to the partial obstruction and soon the effect of the band cannot be felt by the patient. As a result the patient stops losing weight and even gains weight. On phases $2 / 3$ we achieve a long and profound effect with each inflation. This effect can be attributed to a certain dysmotility caused by exhaustion of the esophagus as a result of increasing difficulty to pass the food into the stomach. This could be demonstrated by the fact that for many of the patients, after a night sleep the esophagus remains "inactive" until the late morning/noon and sometimes afternoon, only then would the patient be able to eat or drink. In addition, a certain food or drink could shorten this latent period and "awaken" the esophagus, afterward the patient will be able to eat and drink.

- Central effect - in addition to these effects the patients report different factors which influence their ability to eat or drink regardless to the part of the day or the volume of the band. The patients describe these effects as spontaneous "closing" or "opening" of the band since the effect could be for better or worse. Examples for these factors could be mental status (depression, stress, anxiety etc.), physical status (illness, pregnancy, fatigue, injury/surgery, etc.) or other causes such as vacation, family events and others. All the above examples imply a central effect of external stimuli which effect the brain, and thus signaling the esophagus to decrease or enhance its activity. These effects are reversible, either by deflation of the band, or spontaneously when the initial effect ceases, even without any change in the volume of the band (see Figure 3).

\section{Conclusions}

Based on the results from our model, as well as our clinical experience, we believe that the results of the LGB are beyond its restrictive nature, and it involves some cognitive and behavioral changes that are long lasting.

- Further understanding of the effect of the LGB on the eating abilities over time will be helpful in improving quality of life 


\section{Emotional external factors

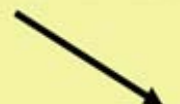

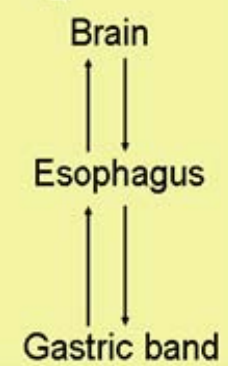

Figure 3: A model of the forces involved in LGB patients.

and there for the compliance to the new and unique eating behavior requirements from the patients.

- Further investigation of the eating habits after LGB is required for establishing more detailed dietary recommendations to these patients.

\section{References}

1. Hensrud DD, Klein S (2006) Extreme obesity: a new medical crisis in the United States. Mayo Clinic Proc 81: S5-S10

2. Buchwald H, Buchwald JN (2002) Evolution of operative procedures for the management of morbid obesity 1950-2000. Obes Surg 12: 705-717.

3. Brolin RE (1996) Update: NIH consensus conference. Gastrointestinal surgery for severe obesity. Nutrition 12: 403-404.

4. Fobi MA (2004) Surgical treatment of obesity: a review. J Natl Med Assoc 96: 61-75.
5. Adams TD, Gress RE, Smith SC, Halverson RC, Simper SC, et al. (2007) Long-Term mortality after gastric bypass surgery. N Eng J Med 357: 753-761.

6. Sjöström L, Narbro K, Sjöström CD, Karason K, Larsson B, et al. (2007) Effects of bariatric surgery on mortality in Swedish obese subjects. N Eng J Med 357: 741-752

7. Kuzmak LI, Thelmo W, Abramson DL, Kral JG (1994) Reversible adjustable gastric banding. Surgical technique. Eur J Surg 160: 569-571.

8. Yitzhak A, Mizrahi S, Avinoach E (2006) Laparoscopic gastric banding in adolescents. Obes Surg 16: 1318-1322.

9. Mizrahi S, Avinoah E (2007) Technical tips for laparoscopic gastric banding: 6 years' experience in 2800 procedures by a single surgical team. Am J Surg 193: 160-165.

10. Taylor CJ, Layani L (2006) Laparoscopic adjustable gastric banding in patients > or $=60$ years old: is it worthwhile? Obes Surg 16: 1579-1583.

11. Chapman AE, Kiroff G, Game P, Foster B, O'Brien P, et al. (2004) Laparoscopic adjustable gastric banding in the treatment of obesity: a systematic literature review. Surgery 135: 326-351.

12. Champault A, Duwat O, Polliand C, Rizk N, Champault GG (2006) Quality of life after laparoscopic gastric banding: Prospective study (152 cases) with a follow-up of 2 years. Surg Laparosc Endosc Percutan Tech 16: 131-136.

13. McGrice MA, Porter JA (2012) What are gastric banding patients eating one year post-surgery? Obes Surg 22: 1855-1858.

14. Kafri N, Valfer R, Nativ O, Shiloni E, Hazzan D (2011) Health behavior, food tolerance, and satisfaction after laparoscopic sleeve gastrectomy. Surg Obes Relat Dis 7: 82-88.

15. Rickers L, McSherry C (2012) Bariatric surgery: nutritional considerations for patients. Nurs Stand 26: 41-48.

16. Thomas JR, Gizis F, Marcus E (2010) Food selections of Roux-en-Y gastric bypass patients up to 2.5 years postsurgery. J Am Diet Assoc 110: 608-612.

17. Lier HØ, Biringer E, Stubhaug B, Tangen T (2012) The impact of preoperative counseling on postoperative treatment adherence in bariatric surgery patients: a randomized controlled trial. Patient Educ Couns 87: 336-342. 